\title{
Antibiotics stewardship in Ghana: a cross- sectional study of public knowledge, attitudes, and practices among communities
}

\author{
Tamara Jimah", Ama P. Fenny ${ }^{2}$ and Oladele A. Ogunseitan ${ }^{1 *}$
}

\begin{abstract}
Background: Antibiotic resistance is a major contributing factor to global morbidity and mortality and is associated with inappropriate medication use. However, the level of antibiotic consumption and knowledge about antibiotic resistance in Ghana is inadequately quantified. Our study identifies strategies for improved stewardship of antibiotics to prevent the proliferation of resistant pathogens by assessing the level of antibiotic knowledge, attitudes, and consumption behaviors by region, gender, age, and education in rural and urban Ghana.

Methods: A cross-sectional study was conducted in 12 communities in the urban Greater Accra and rural Upper West regions of Ghana. A questionnaire survey was administered to 400 individuals aged 18 years and older in selected locations during September-October 2018 to collect data on individual knowledge, attitudes, and practices concerning antibiotics and antibiotic resistance. Multivariate analysis was used to investigate the association between demographic characteristics and knowledge, attitudes, and related behaviors.

Results: Over 30\% (125/400) had not received a doctor's prescription during their last illness. Seventy percent (278/ 400) had taken at least one antibiotic in the year prior to the survey. The top five frequently used antibiotics were Amoxicillin, Amoxicillin-clavulanic acid, Ampicillin, Ciprofloxacin, and Metronidazole. Women and older adults had higher knowledge compared to their respective counterparts $(p<0.01)$. Furthermore, prudent antibiotic use was significantly more prevalent in women than men $(p<0.05)$. Although no regional differences were found in overall knowledge, compared to urban residents, individuals residing in rural settings exhibited higher knowledge about the ineffectiveness of antibiotics for viruses like the cold and HIV/AIDS $(p<0.001)$. Two hundred and fifty-two (63\%) respondents were unaware of antibiotic resistance. There was generally a low level of self-efficacy among participants regarding their role in preserving the effectiveness of antibiotics.
\end{abstract}

Conclusion: Antibiotic knowledge, attitudes, and use varied significantly across demographics, suggesting a contextspecific approach to developing effective community interventions.

Keywords: Antibiotic resistance, Attitudes, Ghana, Knowledge, Stewardship

\footnotetext{
* Correspondence: Oladele.ogunseitan@uci.edu

'Department of Population Health \& Disease Prevention, Anteater Instruction and Research Building, University of California, 653 E Peltason Drive, Irvine,

CA 92697, USA

Full list of author information is available at the end of the article
}

(c) The Author(s). 2020 Open Access This article is licensed under a Creative Commons Attribution 4.0 International License, which permits use, sharing, adaptation, distribution and reproduction in any medium or format, as long as you give appropriate credit to the original author(s) and the source, provide a link to the Creative Commons licence, and indicate if changes were made. The images or other third party material in this article are included in the article's Creative Commons licence, unless indicated otherwise in a credit line to the material. If material is not included in the article's Creative Commons licence and your intended use is not permitted by statutory regulation or exceeds the permitted use, you will need to obtain permission directly from the copyright holder. To view a copy of this licence, visit http://creativecommons.org/licenses/by/4.0/. 


\section{Background}

Resistance of bacterial pathogens to standard antibiotic therapy is a major component of the broader emergence of the Antimicrobial Resistance (AMR) menace that is threatening gains made over the past century to curb the global burden of disease, particularly in Africa [1-4]. Although AMR is widespread, a disproportionate burden is faced by low and middle-income countries where infectious diseases remain a serious life threat [5-8]. Without appropriate and urgent health interventions, Africa, in particular, is projected to carry one of the greatest burdens with over 4 million AMR-attributable deaths each year [8].

The AMR challenge is further exacerbated by globalization and an increase in transnational travel and trade which inevitably create opportunities for the rapid spread of infectious pathogens $[9,10]$. Recognizing the interconnectedness of health issues subsequently gave rise to the One Health $(\mathrm{OH})$ approach which aims to promote cross-sectoral cooperation at the subnational, national and international levels [11]. Antimicrobial resistance risk mitigation requires a $\mathrm{OH}$ response. Undoubtedly, the collaborative effort of a broad array of stakeholders, as well as an understanding of the different sources from which antibiotic resistance emerges and spreads will be required to successfully address this urgent population health problem. The Global Health Security Agenda (GHSA)/Joint External Evaluation (JEE) is one such multinational collaborative effort aimed at preventing, detecting, and responding to infectious disease outbreaks [12]. According to the JEE country-specific reports, Ghana appears to be particularly vulnerable to AMR, reporting a low score of 1 out of 5 points in three of the four AMR indicators [13]. Moreover, these scores were comparable with other West African countries of Cote d'Ivoire, Sierra Leone, and Liberia. Hence, findings from our study may be beneficial to nations with similar conditions. In Ghana, malaria, HIV/AIDS, and bacterial infections including tuberculosis and lower respiratory infections are ranked among the top ten causes of disability-adjusted life years (DALYs) [14]. Moreover, a comparison of DALYs across eleven countries worldwide revealed that Ghana's total DALYs for the aforementioned infections was significantly higher than the mean [14]. Furthermore, increasing trends in AMR rates in Ghana, evidenced by clinical studies, further reflect this concern $[2,15]$. An estimated $41 \%$ of outpatients in Ghana receive at least one antibiotic [2]. This rate is similar to India's, a region reporting the highest antibiotics consumption in the last decade and having one of the highest burdens of antibiotic resistance, globally [16].

While drug resistance is the product of multiple, systemic processes, one of the most common determinants is individuals' compliance to prescriptions and prudent use, and hence introduces a behavior change requirement [17-19]. Studies on knowledge, attitudes, and practices (KAP) have been instrumental in understanding the underlying predictors of health behavior [4, 2025]. For example, in a systematic review that included 26 antibiotic-related studies conducted among the general public worldwide, about one-third (34\%) of those sampled were unaware of the efficacy of antibiotics for bacterial infections, or that resistance could result from misuse of medications [25]. We therefore sought to determine whether these results were mirrored in the Ghanaian context. Despite the existence of guidelines restricting excessive levels of antibiotic dispensing in Ghana, poor enforcement has rendered guidelines ineffective [26], thereby resulting in misuse of antibiotics in communities. A few studies have shown high rates of antibiotic resistance in rural Ghana [27, 28], which may be tied to the low level of educational attainment in these regions as reported in the Demographic and Health Survey (DHS) [29]. Hence, the imperative to closely examine within-country disparities. Particularly, study outcomes will be informative for the design of stewardship programs in line with the ongoing implementation of the country's AMR National Action Plan (NAP), which was developed based on the $\mathrm{OH}$ approach and has as a key objective awareness creation and public education on antibiotic resistance.

\section{Methods}

\section{Study setting and recruitment}

Ghana has a population of about 30 million, of which $54.8 \%$ is urban [14]. Life expectancy for women and men was 68.4 years and 62.6 years, respectively in 2017 [14]. Study participants were recruited from two regions; one predominantly urban and representing the southern province (Greater Accra region (GAR)), and the other predominantly rural and representing the northern province (Upper West region (UWR)). The GAR houses the nation's political capital, Accra, and records a population of 4,010,054 [30]. The UWR occupies the north-western corner of the country, with a population of 702,110 [30]. We employed a cross-sectional study design which included 12 communities in the capital towns of the GAR and UWR, i.e., Accra (8 sites) and Wa (4 sites), respectively. A total of 400 surveys were completed, 200 per region, with each interview lasting about 20-30 min. A questionnaire survey was administered in selected locations during September-October 2018 to gather data on individual knowledge, attitudes, and practices concerning antibiotics and antibiotic resistance. Eligibility was restricted to adults aged 18 years and older who had used antibiotics in the past and were able to speak, read, or understand English or any of the predominantly spoken languages in the regions, i.e., Ga, Akan, Dagaare, 
or Waale [30]. In-person surveys were administered at university campuses, shopping malls, market centers, and hospital surroundings. Individuals were purposely selected at different locations, days, and times of the week to obtain views from across diverse demographic groups. We also endeavored to obtain a balance in gender representation by setting at least $45 \%$ female participation. Participants were screened and recruited by trained research assistants (RA). Upon completion, participants received a soft drink and informational leaflets on antibiotic resistance.

\section{Survey instrument and measures}

We adapted the Antibiotic Resistance: Multi-Country Public Awareness Survey, developed and validated by the World Health Organization (WHO) [4]. The original survey instrument was enhanced by including questions such as the specific antibiotics participants had used during the last time of infection, their preferred method of receiving treatment, as well as preference for payment of treatment and medicines. The survey was first administered in twelve low-and high-income countries in 2015 and showed distinct results among various population groups [4]. To increase content validity, the survey was pilot-tested with 15 volunteers to better understand participants' comprehension. A few questions were subsequently revised prior to final dissemination. Pilot participants were excluded from the analysis. The 29question survey targeted individual knowledge, attitudes, and practices, and composed of both nominal and ordinal closed-ended questions on participant demographics (8 items), access and use of antibiotics (10 items), as well as knowledge and perceptions about antibiotics and antibiotic resistance (11 items).

\section{Dependent variables}

Three outcomes were examined- Knowledge, Attitudes, and Practices. Knowledge was examined based on the number of correct responses to ten questions regarding different infections that could be treated with antibiotics, three questions relating to knowledge about prudent use of antibiotics, and eight questions about antibiotic resistance. For example, Question: "It's ok to use antibiotics that were given to a friend or family member, as long as they were used to treat the same illness"; Question: "It's ok to buy the same antibiotics, or request these from a doctor if you're sick and they helped you get better when you had the same symptoms." Response: True/False/I don't know. The outcome ranged from 0 to 21, with a higher score indicating better knowledge. Attitudes was defined on a Likert scale and determined whether a person agreed strongly, agreed slightly, neither agreed nor disagreed, disagreed slightly, or disagreed strongly with a set of six statements regarding one's perceptions about actions to reduce antibiotic resistance. An average score was determined, ranging from 1 to 5 . The final dependent variable, Practices, was based on a total score for three items that assessed appropriate use of antibiotics. For example, Question: "On that occasion did you get the antibiotics (prescription) from a doctor?"; Question: "On that occasion did you get advice from a doctor, nurse, or pharmacist on how to take them?" Response: Yes/No/Cannot remember. We made a similar decision for Practices as for Knowledge, where any response other than the correct was considered incorrect. Antibiotic use (Practices) was defined appropriate only if one correctly answered all three questions, and inappropriate if otherwise.

\section{Independent variables}

We selected four main independent variables to include in our analysis; place of residence/region (Greater Accra, Upper West), gender (female, male), education (primary or lower, junior high school, senior high/vocational school, tertiary (university degree or currently enrolled)), and age (18-24; 25-34; 35-44; 45-54; 55-64; 65+). This was based on similar KAP studies which found significance for these variables [20, 23, 31].

\section{Data analysis}

We first examined several of the individual items for the Knowledge, Attitudes, and Practices outcome variables separately to understand the percent breakdown in our overall sample. Then we looked at the differences in responses to individual items by region, gender, age, and education using Chi-square and unadjusted regression analyses. We conducted three regression models to examine differences in Knowledge, Attitudes, and Practices scores by the demographic characteristics of interest (region, gender, age, and education), starting with unadjusted models, followed by multivariate analysis using ordinary least squared regression models for the Knowledge and Attitudes outcomes, and logistic regression for the Practices outcome to derive estimates net of other covariates. We retained the same independent variables in all models. Data were analyzed using Stata/SE 15.1.

\section{Results}

Table 1 below presents a description of participants in the study. The sample $(n=400)$ had an equal representation from both regions, with $26(6.5 \%)$ more male respondents than female. Over half of the participants were between the ages of 18 and 34 years. Two-hundred and nineteen $(55 \%)$ had received a university degree or were currently enrolled in one. In comparison with the UWR, the GAR had 56 more residents who had at least a senior high or vocational school degree. Further, more 
Table 1 Description of the sample $(n=400)$

\begin{tabular}{|c|c|c|c|c|}
\hline \multirow[t]{2}{*}{ Independent variables } & \multirow{2}{*}{$\begin{array}{l}\text { Total } \\
\text { n (\%) }\end{array}$} & \multicolumn{3}{|c|}{ Dependent variables } \\
\hline & & $\begin{array}{l}\text { Knowledge } \\
\text { Mean (SD) }\end{array}$ & Attitudes Mean (SD) & $\begin{array}{l}\text { Practices } \\
\text { n (\%) }\end{array}$ \\
\hline \multicolumn{5}{|l|}{ Region } \\
\hline Greater Accra & $200(50.00)$ & $11.23(3.46)$ & $4.44(0.38)$ & $133(66.50)$ \\
\hline Upper West & $200(50.00)$ & $11.67(3.64)$ & $4.34(0.52)$ & $128(64.00)$ \\
\hline \multicolumn{5}{|l|}{ Gender } \\
\hline Male & $213(53.25)$ & $11.02(3.70)$ & $4.37(0.46)$ & $129(60.56)$ \\
\hline Female & $187(46.75)$ & $11.93(3.32)$ & $4.41(0.46)$ & $132(70.59)$ \\
\hline \multicolumn{5}{|l|}{ Age } \\
\hline $18-24$ & $129(32.25)$ & $10.24(3.40)$ & $4.43(0.39)$ & 75 (58.14) \\
\hline $25-34$ & $134(33.50)$ & $11.54(3.83)$ & $4.40(0.45)$ & $86(64.18)$ \\
\hline $35-44$ & $67(16.75)$ & $12.42(2.95)$ & $4.44(0.45)$ & $51(76.12)$ \\
\hline $45-54$ & $38(9.50)$ & $12.68(2.99)$ & $4.31(0.56)$ & $29(76.32)$ \\
\hline $55-64$ & $25(6.25)$ & $12.72(3.02)$ & $4.23(0.42)$ & $17(68.00)$ \\
\hline $65+$ & $7(1.75)$ & $11.29(4.72)$ & $3.98(0.95)$ & $3(42.86)$ \\
\hline \multicolumn{5}{|l|}{ Education } \\
\hline Primary school or lower & $52(13.00)$ & $11.77(3.36)$ & $4.16(0.63)$ & $38(73.08)$ \\
\hline Junior high school & $22(5.50)$ & $12.95(3.02)$ & $4.37(0.39)$ & $13(59.09)$ \\
\hline Senior high/vocational school & $107(26.75)$ & $11.78(3.51)$ & $4.33(0.45)$ & $72(67.29)$ \\
\hline Tertiary (university degree or currently enrolled) & $219(54.75)$ & $11.06(3.78)$ & $4.47(0.40)$ & $138(63.01)$ \\
\hline
\end{tabular}

than twice as many women than men had no formal education; 28 (15\%) women compared to 11 (5\%) men.

\section{Knowledge}

Figure 1 shows regional differences in knowledge about treatment with antibiotics. Given the varying levels of formal education in our sample, as well as to ensure clarity about what antibiotics are, participants were presented with physical samples of commonly used antibiotics purchased over-the-counter and asked whether they thought each of the infections listed could be treated with similar drugs. Two-thirds and one-fourth of respondents were not aware that antibiotics were inactive against viruses like the cold/flu and HIV/AIDS, respectively. Also, 183 (46\%) incorrectly answered that antibiotics were effective against malaria. Overall, individuals in the younger age category, i.e., 18-24 years, had lower antibiotic knowledge compared to those in the older categories. Another was the high number of respondents who believed antibiotics were effective against

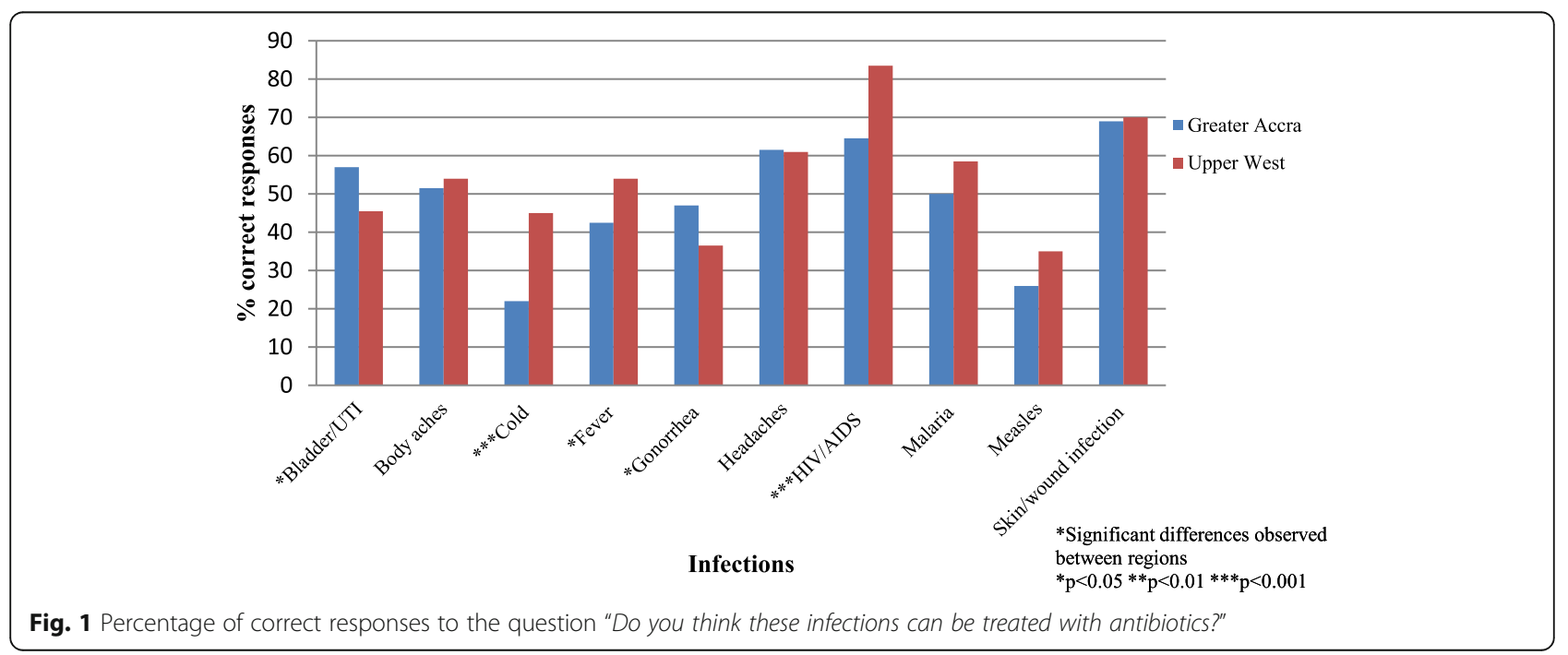


headaches (39\%; 155/400). Regarding knowledge about antibiotic resistance, only 148 (37\%) of respondents had heard of the term, and less than 10\% had heard of "superbugs" or "AMR". Also, when asked whether participants were aware of the World Antibiotic Awareness Week (WAAW) campaign in 2017, only $67(17 \%)$ responded in the affirmative. Twice as many residents of the UWR than GAR was familiar with the campaign.

\section{Regression}

Generally, bivariate and multivariate results were comparable, with significant differences observed for gender and age. Women had 0.31 points higher on the Knowledge scale compared to men $(p<0.01 ; 95 \%$ CI: $0.12-0.50)$ (Table 2). Older age was also found to be a predictor of higher knowledge $(p<0.001)$. However, we found no effect of place of residence on overall knowledge.

\section{Attitudes}

It is observed from Table 3 that the majority of respondents had a positive attitude regarding the importance of childhood vaccinations, handwashing practices, and using only prescribed antibiotics. However, almost half believed there was not much they could do to stop antibiotic resistance.

\section{Regression}

Table 4 examines differences in mean Attitudes score by region, gender, age, and education. Fairly similar associations were observed in the unadjusted and adjusted models, with negative associations observed for region and age, and positive associations for gender and education. Nonetheless, significant differences were observed for only education in the multivariate model net of the other covariates. Individuals with a senior high school/vocational education and tertiary education, on average, had significantly higher scores $(p<0.05 ; 95 \%$ CI: $0.01-0.72$ and $p<0.001 ; 95 \% \mathrm{CI}$ : $0.30-1.02$, respectively) compared to the referent primary/lower education group.

\section{Practices}

In the last year prior to the survey, $132(66 \%)$ and 146 (73\%) of GAR and UWR residents, respectively, had taken at least one antibiotic. Of these, more men than women reported taking antibiotics. Further, 275 (69\%) received a doctor's prescription, while 95 (24\%) assumed it was alright to share antibiotics with friends and family. The majority of participants without a doctor's prescription purchased antibiotics from a pharmacy $(81 \% ; 101 / 125)$. Moreover, some individuals had used more than one type of antibiotic, with

Table 2 OLS results for Knowledge $(n=400)$

\begin{tabular}{|c|c|c|c|c|}
\hline \multirow[t]{2}{*}{ Covariate } & \multicolumn{2}{|c|}{ Unadjusted } & \multicolumn{2}{|c|}{ Adjusted } \\
\hline & $B$ & $95 \% \mathrm{Cl}$ & $B$ & $95 \% \mathrm{Cl}$ \\
\hline \multicolumn{5}{|l|}{ Region } \\
\hline \multicolumn{5}{|l|}{ Greater Accra (ref. group) } \\
\hline Upper West & 0.13 & $(-0.07,0.32)$ & 0.17 & $(-0.04,0.38)$ \\
\hline \multicolumn{5}{|l|}{ Gender } \\
\hline \multicolumn{5}{|l|}{ Male (ref. group) } \\
\hline Female & $0.26^{*}$ & $(0.06,0.45)$ & $0.31^{* *}$ & $(0.12,0.50)$ \\
\hline \multicolumn{5}{|l|}{ Age } \\
\hline \multicolumn{5}{|l|}{ 18-24 (ref. group) } \\
\hline $25-34$ & $0.37^{* *}$ & $(0.13,0.60)$ & $0.43^{* * *}$ & $(0.19,0.66)$ \\
\hline $35-44$ & $0.61^{* * *}$ & $(0.33,0.90)$ & $0.65^{* * *}$ & $(0.35,0.95)$ \\
\hline $45-54$ & $0.68^{* * *}$ & $(0.34,1.04)$ & $0.80^{* * *}$ & $(0.43,1.18)$ \\
\hline $55-64$ & $0.70^{* *}$ & $(0.28,1.12)$ & $0.79 * * *$ & $(0.36,1.21)$ \\
\hline $65+$ & 0.29 & $(-0.45,1.03)$ & 0.46 & $(-0.29,1.24)$ \\
\hline \multicolumn{5}{|l|}{ Education } \\
\hline \multicolumn{5}{|l|}{ Primary/lower (ref. group) } \\
\hline Junior high school & 0.33 & $(-0.16,0.83)$ & 0.45 & $(-0.04,0.94)$ \\
\hline Senior high/vocational school & 0.002 & $(-0.33,0.33)$ & 0.35 & $(-0.003,0.70)$ \\
\hline Tertiary & -0.20 & $(-0.50,0.10)$ & 0.28 & $(-0.07,0.64)$ \\
\hline
\end{tabular}

${ }^{*} p<0.05{ }^{* *} p<0.01{ }^{* * *} p<0.001$ 
Table 3 Attitudes towards actions to reduce antibiotic resistance $(n=400)$

\begin{tabular}{|c|c|c|c|c|c|}
\hline Statements & $\begin{array}{l}\text { Agree } \\
\text { strongly } \\
\mathrm{n}(\%)\end{array}$ & $\begin{array}{l}\text { Agree } \\
\text { slightly } \\
\mathrm{n}(\%)\end{array}$ & $\begin{array}{l}\text { Neither agree nor } \\
\text { disagree } \\
\mathrm{n}(\%)\end{array}$ & $\begin{array}{l}\text { Disagree } \\
\text { slightly } \\
\mathrm{n}(\%)\end{array}$ & $\begin{array}{l}\text { Disagree } \\
\text { strongly } \\
\mathrm{n}(\%)\end{array}$ \\
\hline $\begin{array}{l}\text { People should use antibiotics only when they are prescribed by } \\
\text { a doctor }\end{array}$ & $348(87.00)$ & $34(8.50)$ & $5(1.25)$ & $9(2.25)$ & $4(1.00)$ \\
\hline $\begin{array}{l}\text { People should not keep antibiotics and use them later for other } \\
\text { illnesses }\end{array}$ & $278(69.50)$ & $29(7.25)$ & $20(5.00)$ & $25(6.25)$ & $48(12.00)$ \\
\hline $\begin{array}{l}\text { Parents should make sure all of their children's vaccinations are } \\
\text { up-to-date }\end{array}$ & $365(91.25)$ & $29(7.25)$ & $5(1.25)$ & 0 & $1(0.25)$ \\
\hline People should wash their hands regularly & $383(95.75)$ & $13(3.25)$ & $3(0.75)$ & 0 & $1(0.25)$ \\
\hline $\begin{array}{l}\text { Doctors should only prescribe antibiotics when they are } \\
\text { needed }\end{array}$ & $361(90.25)$ & $29(7.25)$ & $4(1.00)$ & $3(0.75)$ & $3(0.75)$ \\
\hline $\begin{array}{l}\text { There is not much people like me can do to stop antibiotic } \\
\text { resistance }\end{array}$ & $110(27.50)$ & $82(20.50)$ & $80(20.00)$ & $46(11.50)$ & $82(20.50)$ \\
\hline
\end{tabular}

one respondent taking up to five antibiotics during their last illness. The top five frequently used antibiotics were Amoxicillin, Amoxicillin-clavulanic acid, Ampicillin, Ciprofloxacin, and Metronidazole.

Among individuals aged 18-34 years, more residents of the GAR than UWR reported prudent antibiotic use (Fig. 2). Also, better use was observed in the 25-34 than 18-24-age group, although this association was not statistically significant (Table 5). Further, older individuals aged 35-44 years were more likely to use antibiotics appropriately compared to the younger referent 18-24-year category (OR: 2.41; $p<0.05$; 95\% CI:(1.19-4.90) (Table 5). Results also showed that women were more likely than men to practice prudent antibiotic use (OR:1.60; $p<0.05$; 95\% CI:1.04-2.48).

Table 4 OLS results for Attitudes towards actions to reduce antibiotic resistance $(n=400)$

\begin{tabular}{|c|c|c|c|c|}
\hline \multirow[t]{2}{*}{ Covariate } & \multicolumn{2}{|c|}{ Unadjusted } & \multicolumn{2}{|c|}{ Adjusted } \\
\hline & $B$ & $95 \% \mathrm{Cl}$ & $\mathrm{B}$ & $95 \% \mathrm{Cl}$ \\
\hline \multicolumn{5}{|l|}{ Region } \\
\hline \multicolumn{5}{|l|}{ Greater Accra (ref. group) } \\
\hline Upper West & $-0.20^{*}$ & $(-0.40,-0.004)$ & -0.05 & $(-0.26,0.16)$ \\
\hline \multicolumn{5}{|l|}{ Gender } \\
\hline \multicolumn{5}{|l|}{ Male (ref. group) } \\
\hline Female & 0.08 & $(-0.12,0.28)$ & 0.15 & $(-0.05,0.34)$ \\
\hline \multicolumn{5}{|l|}{ Age } \\
\hline \multicolumn{5}{|l|}{ 18-24 (ref. group) } \\
\hline $25-34$ & -0.06 & $(-0.30,0.18)$ & 0.01 & $(-0.23,0.25)$ \\
\hline $35-44$ & 0.02 & $(-0.27,0.32)$ & 0.19 & $(-0.12,0.49)$ \\
\hline $45-54$ & -0.26 & $(-0.62,0.10)$ & 0.002 & $(-0.38,0.38)$ \\
\hline $55-64$ & -0.42 & $(-0.85,0.002)$ & -0.18 & $(-0.61,0.26)$ \\
\hline $65+$ & $-0.98^{*}$ & $(-1.74,-0.23)$ & -0.55 & $(-1.32,-0.22)$ \\
\hline \multicolumn{5}{|l|}{ Education } \\
\hline \multicolumn{5}{|l|}{ Primary/lower (ref. group) } \\
\hline Junior high school & 0.47 & $(-0.02,0.95)$ & 0.40 & $(-0.10,0.89)$ \\
\hline Senior high/vocational school & $0.38^{*}$ & $(0.06,0.71)$ & $0.36^{*}$ & $(0.01,0.72)$ \\
\hline Tertiary & $0.69^{*}$ & $(0.39,0.99)$ & $0.66^{* * *}$ & $(0.30,1.02)$ \\
\hline
\end{tabular}




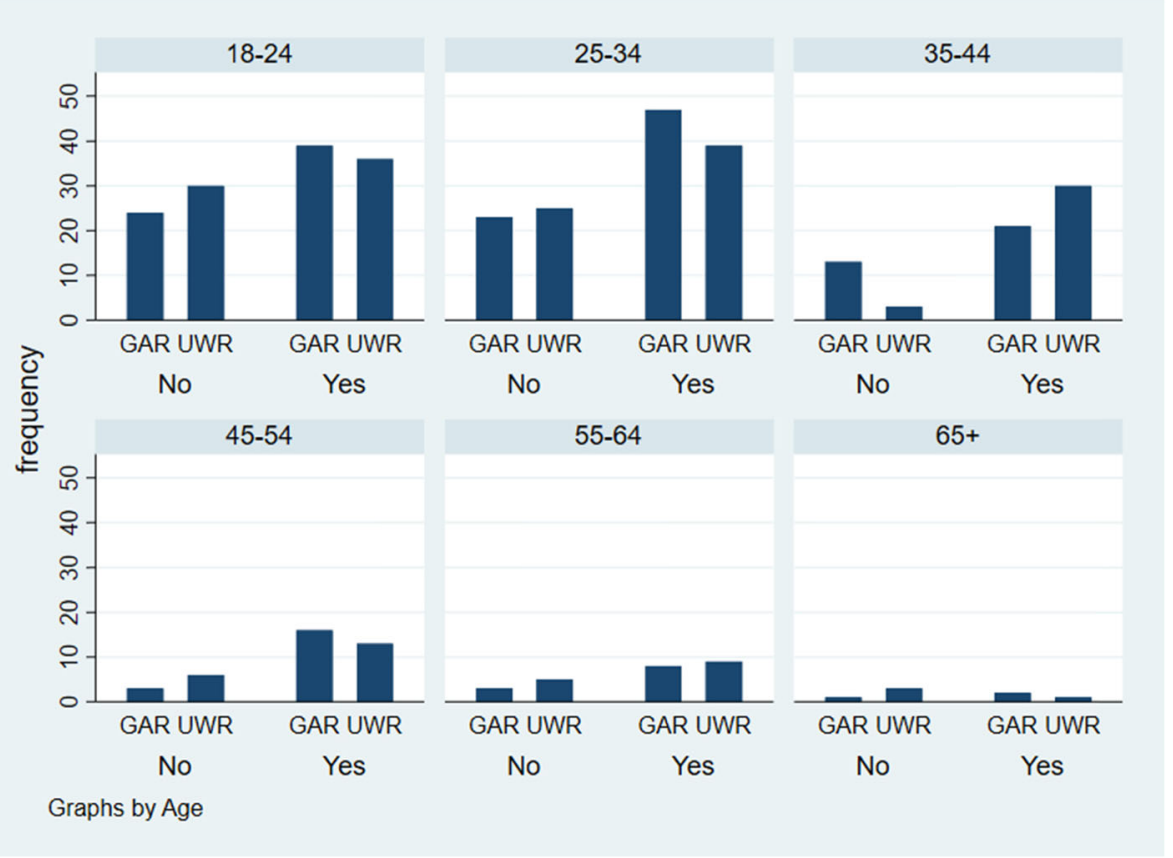

Fig. 2 Appropriate antibiotic use by age and region

\section{Regression}

Table 5 Logistic regression results for Practices $(n=400)$

\begin{tabular}{|c|c|c|c|c|}
\hline \multirow[b]{2}{*}{ Covariate } & \multicolumn{2}{|c|}{ Unadjusted } & \multicolumn{2}{|c|}{ Adjusted } \\
\hline & OR & $95 \% \mathrm{Cl}$ & OR & $95 \% \mathrm{Cl}$ \\
\hline \multicolumn{5}{|l|}{ Region } \\
\hline \multicolumn{5}{|c|}{ Greater Accra (ref. group) } \\
\hline Upper West & 0.90 & $(0.59,1.35)$ & 0.90 & $(0.56,1.40)$ \\
\hline
\end{tabular}

Male (ref. group)

Female

$1.56^{*} \quad(1.03,2.37) \quad 1.60^{*} \quad(1.04,2.48)$

Age

18-24 (ref. group)

$25-34$
$35-44$
$45-54$
$55-64$
$65+$

Education

Primary/lower (ref. group)

\begin{tabular}{lcccc} 
Junior high school & 0.53 & $(0.19,1.52)$ & 0.49 & $(0.16,1.47)$ \\
Senior high/vocational school & 0.76 & $(0.36,1.58)$ & 0.90 & $(0.40,2.08)$ \\
Tertiary & 0.63 & $(0.32,1.23)$ & 0.83 & $(0.36,1.89)$ \\
\hline Statistical significance: ${ }^{*} p<0.05{ }^{* *} p<0.01{ }^{* * *} p<0.001$ & &
\end{tabular}

\section{Discussion}

Knowledge

Most study participants acknowledged the importance of using antibiotics only prescribed by a doctor. However, not all participants received a prescription during their last illness, which suggests that knowledge does not necessarily translate to good practice. This finding underscores the challenge of changing human behavior and suggests the need for new approaches to promote better stewardship of antibiotics at the community level. Similar to previous studies [20,31, 32], women in our sample had higher knowledge compared to men. Of particular concern was the high proportion of younger individuals who had used antibiotics in the year preceding the survey, given the lower level of knowledge observed in this group. This was also reflected in the WHO study which found higher use among the young [4]. Furthermore, studies in Asia and Europe have identified variations within demographics, reporting better knowledge observed among women, older adults, and urban residents [20, 22-24]. We did not find a statistically significant association between education and knowledge. This is particularly important given that loweducational attainment may result in lower knowledge about antibiotic resistance and could lead to inappropriate use of antibiotics. Nonetheless, some studies have reported misuse of antibiotics among persons with higher levels of education [20-22]. Although the association was not significant, we did observe a lower mean score among those with a 
university degree or currently enrolled in one compared to the referent group. This emphasizes the need for continued targeted health promotion in specific population groups, e.g., incorporating AMR-related information into the academic curricula.

The absence of an association between place of residence and overall knowledge could be attributed to the fact that although the UWR is predominantly rural, its capital town, Wa, may exhibit some urban characteristics in comparison to the rest of the region. Hence, surveying other communities beyond the Wa vicinity may yield differences. Nonetheless, we did find significance in terms of individual items regarding knowledge about infections that did not require antibiotic therapy (Fig. 1); residents of the rural UWR exhibited better knowledge compared to the urban GAR. There may have been successful efforts to create awareness on antibiotic resistance in the capital of Wa, given that twice as many residents of the UWR than GAR had heard about the WAAW. This may have explained the higher knowledge observed among residents of the UWR. Despite higher knowledge among UWR residents about infections not requiring antibiotics, this did not translate to more prudent use. Further research is therefore needed to determine which factors comprise strong predictors of behavior change to ensure that individuals obtain a medical diagnosis and prescription at the onset of illness. More concerning, though, was the number of individuals, particularly the younger-aged, who thought antibiotics were effective against viruses, headaches, and malaria. This erroneous belief could have stemmed from the fact that during malaria episodes one may also be co-infected with a bacterial infection thereby requiring antibiotic prescription $[33,34]$. The use of antibiotics for the treatment of non-bacterial infections, particularly those endemic to the country, could provoke dire consequences for communities. Hence, recognizing that previous prescriptions by physicians could potentially inform self-medication behaviors [21], our results provide opportunities for more targeted interventions.

\section{Attitudes}

The average Attitudes score of over 4.39 out of 5 suggests that, overall, individuals had a positive perception about important steps to reduce the spread of antibiotic-resistant pathogens. However, the large number of participants who believed there was not much they could do to stop antibiotic resistance reflects low self-efficacy and calls for tailored approaches to reach the public. Compared to individuals with only a primary education or lower, persons with a tertiary education showed more positive attitudes towards actions to reduce antibiotic resistance, reiterating the need to reach the most vulnerable. Continuous public awareness remains paramount, given that many were unaware about their role in alleviating resistance despite adequate understanding of the importance of using antibiotics prudently.

\section{Practices}

An important aspect of the original study which our survey sought to further develop was to identify a list of frequently used antibiotics by the public. We found our list to be similar to that of Versporten and colleagues [3] who reported that the commonly prescribed antibiotics in Africa included Amoxicillin, Ciprofloxacin, and Metronidazole. Likewise, Amoxicillin and Ampicillin were among the most frequently used antibiotics consumed by tertiary students in Ghana [21]. It is worth noting that the aforementioned antibiotics are used in the treatment of lower respiratory infections, urinary tract infections, and meningitis, all of which constitute the top causes of premature death and years lived with disability in Ghana [14]; hence, the need to preserve the efficacy of existing antibiotics.

Our results also shed light on the problematic issue of self-medication and access to antibiotics without prescription [21, 22]. About a quarter of participants of the general public in our study and that of the WHO [4] assumed it was alright to use antibiotics given them by friends and family. Without the right medical attention, individuals are more likely to misuse antibiotics. Moreover, more than $80 \%$ of participants in other studies [4, 24] reported having been prescribed antibiotics by a doctor, compared to only 275 (69\%) of our participants who had received a formal prescription. Over $80 \%$ of those without a doctor's prescription purchased antibiotics directly from a pharmacy, reiterating the pertinent role of pharmaceutical dispensaries in regulating the sale of antibiotics. Also, more men than women reported taking antibiotics in the last year. This raises concern because our findings showed that men had lower knowledge than women and were less likely to use antibiotics appropriately ( $p<0.05$; 95\% CI: $1.04-2.48)$.

\section{Strengths and limitations of the study}

Our study has several strengths. This is the first extensive survey conducted in the Greater Accra and Upper West regions of Ghana to examine public use of antibiotics, as well as the level of knowledge and attitudes towards antibiotic resistance. We enhanced the original survey instrument by inquiring about specific antibiotics used during the last time of infection. In addition, our study provided a snapshot of both the rural-north and urban-south settings, allowing for more tailored interventions. Still, our study has some limitations. First, the study included residents from two regions, hence, findings are not generalizable to the rest of the country. Nonetheless, our sample composition was found to be comparable with Ghana's DHS [29] data in terms of educational attainment, and had about an equal representation of men and women. Also, since cross-sectional 
studies represent one point in time, they are limited in their ability to reflect changes in knowledge and behavior over time. Finally, the closed-ended survey format inevitably limits further elaboration of responses. We therefore anticipate that our findings will form the basis for future studies aimed at exploring individuals' perceptions in relation to antibiotic use.

\section{Conclusion}

To the best of our knowledge, this study is the first to compare antibiotic knowledge, attitudes, and practices in diverse population groups within both the rural northern and urban southern regions, while identifying specific types of antibiotics frequently used. Our study sheds light on the need to create targeted health interventions particularly for younger individuals and the male population, given the prevalence of low knowledge and inappropriate antibiotic use in these groups. For instance, women may be more likely to access healthcare facilities given their role as caretakers, which may have explained the higher level of knowledge observed in this group. We therefore propose expansion of sustained public educational programs. As indicated by our findings, participants who had heard of the WAAW campaign exhibited better knowledge about antibiotic resistance. We also suggest that further studies be conducted to explore the reasons for non-compliance despite one's knowledge about appropriate behavior. Another important factor worth examining is the influence of community pharmacists and doctors given their pertinent role as dispensers. In addition, we found low levels of self-efficacy among participants regarding their ability to contribute to the reduction of antibiotic resistance. Hence, community health interventions would benefit from incorporating relatable and applicable strategies that can be easily adopted by individuals. One of the strategic objectives of Ghana's five-year NAP is to educate the public on responsible use of antimicrobials, with related activities currently set for 2018-19. Extending efforts through subsequent years would be helpful to ensure individuals receive consistent and up-to-date health information.

\footnotetext{
Abbreviations

AMR: Antimicrobial Resistance; DALYs: Disability-adjusted Life Years: DHS: Demographic and Health Survey; GAR: Greater Accra Region; GHSA: Global Health Security Agenda; JEE: Joint External Evaluation; KAP: Knowledge, Attitudes, and Practices; NAP: National Action Plan; OH: One Health; RA: Research Assistant; UWR: Upper West Region; WAAW: World Antibiotic Awareness Week; WHO: World Health Organization

\section{Acknowledgements}

We are grateful to the Department of Population Health \& Disease Prevention at the University of California, Irvine for the funding provided to undertake the study. We would also like to thank the WHO for granting permission to adapt the original survey. The authors express their utmost gratitude to Dr. Annie Ro for her guidance during the preparation of the manuscript, and to all study participants and research assistants (Justin Bamora, Sabina Bapono, Mohammed Ibrahim, Priscilla Manu Larbi, William Ofosu, Augustina Vi-ire,
}

Ebo Abbiw-Williams, Monica Yere), without whom this study would not have been possible.

\section{Authors' contributions}

All authors contributed to the study design and review of the manuscript. The study idea was conceptualized by TJ and OAO. Data collection was supervised by TJ and APF. Data were managed and analyzed by TJ. All authors reviewed, contributed, and approved the final manuscript.

\section{Funding}

This research study was funded by the Department of Population Health \& Disease Prevention at the University of California, Irvine. The funder had no role in the collection, analysis, and interpretation of the data.

\section{Availability of data and materials}

The dataset used for the current study is available from the corresponding author on reasonable request.

\section{Ethics approval and consent to participate}

Ethical approval was obtained from the Ethics Committee of the Institute of Statistical, Social, and Economic Research at the University of Ghana, Legon (ECH 106/17-18), and the Institutional Review Board of the University of California, Irvine Office of Research (HS\# 2018-4325). All RA completed ethical conduct training, including survey content, data quality, participant recruitment, and interview procedures.

\section{Consent for publication}

Participation was voluntary and each respondent provided verbal consent prior to the survey. No identifiable information was collected from participants.

\section{Competing interests}

The authors declare that they have no competing interests.

\section{Author details}

${ }^{1}$ Department of Population Health \& Disease Prevention, Anteater Instruction and Research Building, University of California, 653 E Peltason Drive, Irvine, CA 92697, USA. ${ }^{2}$ Institute of Statistical, Social and Economic Research, University of Ghana, Legon, Accra, Ghana.

Received: 21 December 2019 Accepted: 11 May 2020

Published online: 18 August 2020

\section{References}

1. Prestinaci F, Pezzotti P, Pantosti A. Antimicrobial resistance: a global multifaceted phenomenon. Pathog Glob Health. 2015;109(7):309-18. https:// doi.org/10.1179/2047773215Y.0000000030

2. Gyansa-Lutterodt M. Antibiotic resistance in Ghana. Lancet Infect Dis. 2013; 13(12):1006-7. https://doi.org/10.1016/s1473-3099(13)70196-8.

3. Versporten A, Zarb P, Caniaux I, Gros MF, Drapier N, Miller M, et al. Antimicrobial consumption and resistance in adult hospital inpatients in 53 countries: results of an internet-based global point prevalence survey. Lancet Glob Health. 2018;6(6):e619-e29. https://doi.org/10.1016/s2214109x(18)30186-4.

4. World Health Organisation. Antibiotic resistance: Multi-country public awareness survey. WHO Press. 2015:1-51. Accessed 3 Sept 2017. Available from: http://apps.who.int/iris/bitstream/10665/194460/1/9789241509817_ eng.pdf?ua=1.

5. Gupta I, Guin P. Communicable diseases in the South-East Asia region of the World Health Organization: towards a more effective response. Bull World Health Organ. 2010;88(3):199-205. https://doi.org/10.2471/blt.09. 065540.

6. GBD 2013 Mortality and Causes of Death Collaborators. Global, regional, and national age-sex specific all-cause and cause-specific mortality for 240causes of death, 1990-2013: a systematic analysis for the Global Burden of Disease Study 2013. Lancet. 2015;385(9963):117-71. https://doi.org/10.1016/s01406736(14)61682-2.

7. Okeke IN, et al. Antimicrobial resistance in developing countries. Part II: strategies for containment. Lancet Infect Dis. 2005;5(9):568-80. https://doi. org/10.1016/s1473-3099(05)70217-6. 
8. O'Neill Jl. Antimicrobial resistance: tackling a crisis for the health and wealth of nations. Rev Antimicrob Resist. 2014;20:1-6.

9. Hawkey PM. Multidrug-resistant gram-negative bacteria: a product of globalization. J Hosp Infect. 2015;89(4):p241-7. https://doi.org/10.1016/j.jhin. 2015.01.008

10. MacPherson DW, Gushulak BD, Baine WB, Bala S, Gubbins PO, Holtom P et al. Population mobility, globalization, and antimicrobial drug resistance. Emerg Infect Dis. 2009;15(11):1727-32.

11. Travis DA, Sriramarao P, Cardona C, et al. One medicine one science: a framework for exploring challenges at the intersection of animals, humans, and the environment. Ann N Y Acad Sci. 2014;1334:26-44.

12. Forzley M. Global Health security agenda: joint external evaluation and legislation-a 1-year review. Health Secur. 2017;15(3):312-9. https://doi.org/10. 1089/hs.2017.0013

13. World Health Organisation. Joint External Evaluation of IHR Core Capacities of the Republic of Ghana. Available from: https://extranet.who.int/sph/sites/ default/files/jeeta/WHO-WHE-CPI-2017.26-eng.pdf. Accessed 1 Jul 2019.

14. Institute for Health Metrics and Evaluation. Ghana | Institute for Health Metrics and Evaluation. 2017. Available from: http://www.healthdata.org/ ghana. Accessed 9 Apr 2019.

15. Opintan JA, Newman MJ, Arhin RE, Donkor ES, Gyansa-Lutterodt M, MillsPappoe W. Laboratory-based nationwide surveillance of antimicrobial resistance in Ghana. Infect Drug Resist. 2015;8:379-89. https://doi.org/10. 2147/idr. S88725.

16. Laxminarayan R, Chaudhury RR. Antibiotic resistance in India: drivers and opportunities for action. PLoS Med. 2016;3(3):e1001974. https://doi.org/10. 1371/journal.pmed.1001974.

17. Zarb P, Goossens H. Human use of antimicrobial agents. Rev Sci Tech. 2012; 31(1):121-33.

18. Kotwani A, Holloway K. Trends in antibiotic use among outpatients in New Delhi, India. BMC Infect Dis. 2011;11:99. https://doi.org/10.1186/1471-2334-11-99.

19. Holmes AH, Moore LS, Sundsfjord A, Steinbakk M, Regmi S, Karkey A, et al. Understanding the mechanisms and drivers of antimicrobial resistance. Lancet. 2016;387(10014):176-87.

20. Demore B, Mangin L, Tebano G, Pulcini C, Thilly N. Public knowledge and behaviours concerning antibiotic use and resistance in France: a crosssectional survey. Infection. 2017;45(4):513-20. https://doi.org/10.1007/ s15010-017-1015-2.

21. Donkor ES, Tetteh-Quarcoo PB, Nartey P, Agyeman IO. Self-medication practices with antibiotics among tertiary level students in Accra, Ghana: a cross-sectional study. Int J Environ Res Public Health. 2012;9(10):3519-29. https://doi.org/10.3390/ijerph9103519.

22. Lv B, Zhou Z, Xu G, Yang D, Wu L, Shen Q, et al. Knowledge, attitudes and practices concerning self-medication with antibiotics among university students in western China. Tropical Med Int Health. 2014;19(7):769-79. https://doi.org/10.1111/tmi.12322

23. McNulty CA, Boyle P, Nichols T, Clappison P, Davey P. Don't wear me out-the public's knowledge of and attitudes to antibiotic use. J Antimicrob Chemother. 2007;59(4):727-38. https://doi.org/10.1093/jac/dkl558.

24. Prigitano A, Romano L, Auxilia F, Castaldi S, Tortorano AM. Antibiotic resistance: Italian awareness survey 2016. J Infect Public Health. 2018;11(1): 30-4. https://doi.org/10.1016/j.jiph.2017.02.010

25. Gualano MR, Gili R, Scaioli G, Bert F, Siliquini R. General population's knowledge and attitudes about antibiotics: a systematic review and metaanalysis. Pharmacoepidemiol Drug Saf. 2015;24(1):2-10. https://doi.org/10. 1002/pds.3716.

26. Yevutsey SK, Buabeng KO, Aikins M, Anto BP, Biritwum RB, Frimodt-Moller $\mathrm{N}$, et al. Situational analysis of antibiotic use and resistance in Ghana: policy and regulation. BMC Public Health. 2017;17(1):896. https://doi.org/10.1186/ s12889-017-4910-7.

27. Saba CKS, Amenyona JK, Kpordze SW. Prevalence and pattern of antibiotic resistance of Staphylococcus aureus isolated from door handles and other points of contact in public hospitals in Ghana. Antimicrob Resist Infect Control. 2017;6:44. https://doi.org/10.1186/ s13756-017-0203-2.

28. Nielsen MV, Sarpong N, Krumkamp R, Dekker D, Loag W, Amemasor S, et al. Incidence and characteristics of bacteremia among children in rural Ghana. PLoS One. 2012;7(9):e44063. https://doi.org/10.1371/journal.pone.0044063.

29. Ghana Statistical Service, Demographic and Health Survey 2014. Available from: https://dhsprogram.com/publications/publication-FR307-DHS-FinalReports.cfm. Accessed 2 Aug 2019.
30. Ghana Statistical Service. 2010 Population \& Housing Census: National Analytical Report. Ghana Statistics Service; 2013.

31. Gu J, Zhao J, Huang Y, Yang W, Ren Z, Li W, et al. Use of antibiotics by urban and rural residents in Heilongjiang Province, China: cross-sectional study. Tropical Med Int Health. 2015;20(12):1815-22. https://doi.org/10.1111/ tmi.12602.

32. McNulty CA, Boyle P, Nichols T, Clappison P, Davey P. The public's attitudes to and compliance with antibiotics. J Antimicrob Chemother. 2007;60(Suppl 1):i63-8. https://doi.org/10.1093/jac/dkm161.

33. Church J, Maitland K. Invasive bacterial co-infection in African children with plasmodium falciparum malaria: a systematic review. BMC Med. 2014;12:31. https://doi.org/10.1186/1741-7015-12-31.

34. Maltha J, Guiraud I, Kabore B, Lompo P, Ley B, Bottieau E, et al. Frequency of severe malaria and invasive bacterial infections among children admitted to a rural hospital in Burkina Faso. PLoS One. 2014;9(2):e89103. https://doi. org/10.1371/journal.pone.0089103.

\section{Publisher's Note}

Springer Nature remains neutral with regard to jurisdictional claims in published maps and institutional affiliations.
Ready to submit your research? Choose BMC and benefit from:

- fast, convenient online submission

- thorough peer review by experienced researchers in your field

- rapid publication on acceptance

- support for research data, including large and complex data types

- gold Open Access which fosters wider collaboration and increased citations

- maximum visibility for your research: over $100 \mathrm{M}$ website views per year

At BMC, research is always in progress.

Learn more biomedcentral.com/submissions 